\title{
Educational Effectiveness, Efficiency, and Equity in Spanish Regions: What Does PISA 2015 Reveal?
}

\author{
Francisco López Rupérez, Isabel García García \\ School of Education, Camilo José Cela University, Madrid, Spain \\ Eva Expósito-Casas \\ School of Education at National University of Distance Education, Madrid, Spain
}

\begin{abstract}
The territorial organization of Spain into regions (autonomous communities) involves a remarkable decentralization. Therefore, it is interesting to make a comparative efficiency analysis of the public spending in education among regions that can to shed light on both the educational policies at the regional level, and the corrective state actions of inter-territorial imbalances. Furthermore, equity of the results of the education system is an indisputable goal of any society that aspires to justice and social cohesion. This research poses, firstly, an estimation of educational effectiveness and efficiency of public spending using a secondary analysis of PISA 2015 data that takes into account the value of ESCS. Subsequently, two educational equity parameters are estimated. The triple empirical categorization of autonomous communities, according to the efficiency and equity results, allows the derivation of policy recommendations of interest both at the regional and central government levels.
\end{abstract}

Keywords: efficiency; equity; public governance; evaluation; PISA 2015

The matter of efficiency in the administration of resources is a constant feature of public governance design and quality by international organisations. According to the definition of the World Bank, "Governance is the manner in which power is exercised in the management of a country's economic resources and social resources for development" (World Bank, 1992, p. 52). Kaufmann, Kraay, and Zoido-Lobatón (1999a, b), based on two research papers written for the above organisation, included in their public governance model, "the capacity of government to manage efficiently". The UN, the European Commission, and the OECD have assumed this doctrine and, often, governance itself has been considered a synonym of efficient management (López Rupérez, García \& Expósito, 2017). The significance of the role of efficiency in public governance is particularly relevant in the case of education. As this is a service which, in developed countries, addresses a fundamental right universal and free for major population age groups - education systems are public policy areas with a massive use of resources. Considering education and training as actual investments does not obviate the issue of efficiency of public expenditure but rather reinforces it (López Rupérez, 2001).

There is robust empirical evidence at an international level regarding the limitations of education expenditure as an unquestionable factor of continuous improvement 
10 of education outcomes (UNESCO, 2004; OECD, 2016). Recently, the OECD, after repeatedly ratifying in its various PISA reports what UNESCO has called the 'spending paradox', concluded that, "As expenditure on educational institutions per student increases, so does a country's mean performance; but the rate of increase diminishes fast, as indicated by the logarithmic scale on the horizontal axis" (OECD, 2016, p. 63).

When we focus on Spain, the question that arises is whether the variable of education expenditure in this country is still a significant factor upon which one should operate systematically in order to provide better education outcomes. While in Spain cumulative spending per student aged 6 to 15 is significant (US \$74,947), regional distribution shows considerable differences between the various autonomous communities (Ministry of Education, Culture and Sports, 2017). This could lead to opportunities to improve outcomes through differential treatment of the regions regarding education spending if we take into account the non-linear relationship between spending per student and academic performance. Given this possibility, it would be essential to previously establish the most comparable picture possible, both of the public education spending of the various autonomous regions and its efficiency, without forgetting the conditions of equity that must have a bearing on the analysis and also on education policy and practice.

Throughout this study we will be addressing, first, a description of the corresponding conceptual and methodological framework. Next, we calculated spending per student in schools financed with public funds by autonomous regions harmonised through correction of the effect of rural schooling, a structural phenomenon which has a significant impact on expenditure. The above harmonisation of public expenditure (inputs) was followed by harmonisation of results (outputs), taking into account in this case regional differences in student socio-economic and cultural status (ESCS). Then, we calculated the efficiency of public expenditure on education in the autonomous communities. We analysed the relationship between wealth, public expenditure on education, and expenditure efficiency, to then proceed to an analysis and discussion of the consequences. This was followed by addressing the issue of educational equity within the autonomous communities, calculating characteristic parameters, diagnosing the situation in this regard in each community, and providing specific proposals for education policies other than those related to spending. Finally, we present a summary of the set of the most significant empirical conclusions and main recommendations in terms of policies for improvement of interest at both the regional and national levels.

\section{The conceptual and methodological framework}

\subsection{A systemic approach}

Starting from Ashby and his cybernetic paradigm (Ashby, 1956), the general functioning of an education system can be described as a combination of a set of inputs 


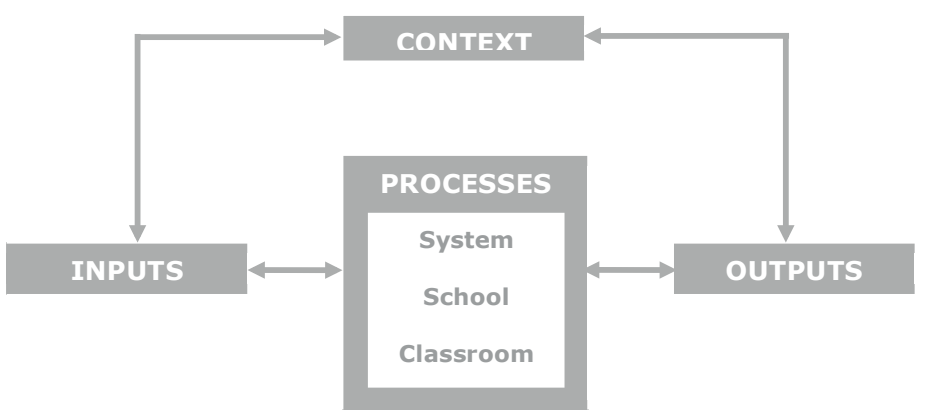

Figure 1 Systemic approach to the description of the education system.

Source: Authors' own work on the basis of an OECD scheme.

which, through a series of internal processes, turn into outputs. The context of education, with its various components, has an impact on the inputs, affects the processes (system, school, and classroom), and conditions achievement of results (Figure 1).

Based on a more complex view of this systemic pattern, which is simple and yet powerful, most of the relationships between components are bidirectional. Thus, processes act retroactively upon inputs, based on how priorities are established and the level of efficiency in their management; and outputs operate in the same way upon processes, in terms of validation or correction, and they do so with an intensity that depends on the level of intelligence of the system as a whole. Smart systems promote, deliberately, the type of feedback that generates positive returns and improves outcome quality. Finally, results have a retroactive effect on the context, at a social and economic level, with broad effects on the medium and long term, although certainly positive if the system is successful.

This study follows the intellectual tradition of a systemic approach, which is originally linked to a description of material systems and biological systems. In this tradition, the idea of efficiency is understood as the quotient between outputs and inputs or, in other words, the amount of outputs the system produces for each input unit. However, in the tradition linked to the economy, in particular - and, by extension, some social sciences - the idea of efficiency has taken on a rather more sophisticated theoretical and operational meaning.

\subsection{Technical efficiency vs. productivity}

The generic idea of efficiency as an output/input ratio is further refined, in the tradition of economics, in at least two other ways: first, introducing a conceptual distinction between 'technical efficiency' and productivity, and second, developing highly sophisticated calculation methods for the first (Mandl, Dierx, \& Ilzkovitz, 2008; Coll Serrano \& Blasco, 2006; Cordero, Salinas \& Pedraja, 2005; Worthington, 2001). Nonetheless, what Cordero, Crespo, Pedraja, and Santín (2011) have pointed 
12 out in relation to these procedures is that education is a highly complex process and there are problems of variable measurement errors, potential unobserved effects or omitted variables, together with the possibility of double causation between dependent and independent variables, all of which can generate endogeneity, which can affect the accuracy of the results.

In this paper we have preferred to use the term 'spending efficiency' to refer to what the scientific community of applied economics calls productivity (OECD, 2001), that is, the ratio between produced outputs and used inputs, so that the greater the output for the given input, or the lesser the input for the output given, the more productive the production unit.

\subsection{The matter of equity}

The matter of equity and social cohesion is a shared concern among developed countries which has led, among other things, to political statements in the European Union, first in connection with the Lisbon Strategy and, later, with the ET2020 Strategy ${ }^{1}$. In turn, the OECD has shown this same sensitivity across a broader geographical area and they have repeatedly expressed an interest in measuring the degree, or level, of equity in all the PISA editions published to date (OECD, 2010; 2014; 2016). The analysis of the relationship between the two variables of socio-economic and cultural status and academic performance helps to assess the level of equity of an education system. This was the line followed by PISA, which is based on the measurement of two characteristic parameters of this statistical relationship: the magnitude of the impact of the first of these two variables on the second one, and the intensity of those relationships.

As is known, the first is defined by the scale of the slope of the line that best fits the corresponding distribution of points upon a Cartesian graph, so that the greater the slope, the greater the difference in scores per socio-economic and cultural index unit (ESCS) (OECD, 2016). The second one measures the strength of the statistical relationship between the two variables, the percentage of performance variance explained by the ESCS variable, or, if we wish, the predictive power which ESCS has over school performance values (OECD, 2016, p. 216).

The education system of an advanced society must certainly aspire to being effective and efficient, but also fair and capable of diminishing the impact of socio-economic and cultural differences in the population on children and adolescent education outcomes, so that the liberal principle of true equal opportunity may become effective at the initial stage of human existence, at the starting line towards adulthood (Flamant, 1988).

1 http://ec.europa.eu/education/policy/strategic-framework_en 


\subsection{The methodological framework}

This paper conducts a secondary analysis of the databases derived from the PISA assessment. The sample (39,066 students) comprises all of the Spanish autonomous communities that took part in the PISA 2015 assessment (all of them have a representative sample). The basic methodological framework of this study follows the systemic approach and, in particular, the pattern described in Figure 1. It is based on a single input, measured by the variable 'public spending per student in non-university educational institutions supported with public funds', and a single output, measured by the variable average score of the three PISA 2015 tests'. PISA provide 10 plausible values (used to measure the performance measurement average) and normalised student final weights (W_FSTUWT), which were used in the analyses carried out, thus providing more efficient estimates.

Moreover, the concern about equity, in the comparison between the various autonomous communities, leads to an analysis of this factor, specific of advanced educational systems, and to qualifying the resulting values of efficiency. In line with the above, the main steps to guide the corresponding calculation procedures will basically be the following:

a) Territorial harmonisation of the input variable for the seventeen Spanish autonomous communities taking into account the Rural Schooling Index (IER).

b) Territorial harmonisation of the output variable by correcting the effect of student Socio-economic and Cultural Status Index (ESCS) over the average PISA 2015 score in each one of the seventeen autonomous communities.

c) Calculation of efficiencies (outputs/inputs) and estimate of gain margins in relation to the average of the autonomous communities.

d) Calculation of parameters that confirm equity of the education systems in the autonomous communities: impact magnitude of socio-economic and cultural status on performance, and the strength or intensity of the statistical relationship between the two variables.

\section{Harmonized public spending per student in non-university educational institutions supported with public funds, by autonomous community}

Hereinafter, public spending per student in non-university educational institutions supported with public funds shall be considered a measurement of system inputstreated here as a synonym for financial resources (Ministry of Education, Culture and Sports, 2017). The calculation method used follows the standards applied by the OECD in its international indicators of education systems (INES). Nonetheless, the notably different degree of rural schooling, as one of the characteristics of the unique context that exists in each autonomous community and whose influence on 
14 education spending can be shown, requires harmonisation of the previous expenditure figures in order to improve homogeneity for comparison.

\subsection{Public spending per student vs. Rural Schooling Index}

As indicated elsewhere (Consejo Escolar del Estado, 2015), the factor that most explains the differences between autonomous communities, as far as the figures of public spending per student in non-university educational institutions supported with public funds are concerned, is the student/teacher ratio. A structural variable that strongly conditions ratio is the level of dispersal of the school population. This is a defining feature of rural areas that can be measured by the percentage of students enrolled in towns with less than 10,000 inhabitants. This percentage has been termed Rural Schooling Index (IER). Even when rurality can be defined by a broader set of traits, for the purposes of this study, this is the most pertinent approach and, furthermore, relatively easy to measure. A linear regression analysis between IER and public spending per student in non-university educational institutions supported with public funds confirms the existence of a direct relationship between the two variables and reveals the strength of such a relationship. This preliminary analysis indicates there is a contextual variable whose influence on expenditure should be harmonised in order to be able to make a comparison of autonomous communities under reasonably standard terms.

\subsection{Comparison of harmonised public spending per student, by autonomous community}

The results of the previous calculations warn about the advisability of considering this demographic contextual variable (IER). In other words, the aim is to calculate each value of public spending per student $(y)$ resulting from standardising the degree of influence of the IER factor $(x)$ in the various autonomous communities. To this end, we conducted the abovementioned regression analysis and then determined, by ordinary least squares (OLS), the best fit equation (1), presenting an $R^{2}$ coefficient of determination of 0.30 and statistical significance $(0.02)$.

$$
y=33.73 x+4.0628
$$

Table 1 shows, in comparative terms for the various autonomous communities, gross values of public spending per student and net values resulting from applying the correction given by the model. As shown in this table, the harmonised values for public spending on education per student show notable differences between the autonomous communities exceeding, 1,400 $€$ at the two ends: Galicia and the Community of Madrid. 
Table 1 Values of the Rural Schooling Index (IER) in Spain and in each autonomous community and gross and corrected values for IER in public spending per student. Academic year: 2013-2014.

\begin{tabular}{lccc}
\hline & $\begin{array}{c}\text { Rural Schooling } \\
\text { Index (IER) }\end{array}$ & $\begin{array}{c}\text { Pross values } \\
\text { (Euro) }\end{array}$ & $\begin{array}{c}\text { Corrected values } \\
\text { (Euro) }\end{array}$ \\
\hline Spain & 18.7 & 4,537 & 4,693 \\
Andalusia & 15.8 & 4,042 & 4,596 \\
Aragón & 23.1 & 4,707 & 4,842 \\
Asturias & 32.8 & 5,530 & 5,169 \\
Balearic Islands & 13.0 & 4,808 & 4,501 \\
Canary Islands & 7.9 & 4,539 & 4,329 \\
Cantabria & 29.4 & 5,623 & 5,054 \\
Castilla-León & 27.1 & 5,109 & 4,977 \\
Castilla-La Mancha & 32.0 & 4,295 & 5,142 \\
Catalonia & 16.5 & 4,198 & 4,619 \\
Community of Valencia & 14.1 & 4,449 & 4,538 \\
Extremadura & 39.7 & 5,276 & 5,402 \\
Galicia & 47.6 & 5,404 & 5,668 \\
La Rioja & 27.7 & 4,827 & 4,997 \\
Community of Madrid & 5.5 & 3,857 & 4,248 \\
Murcia & 25.1 & 4,352 & 4,909 \\
Navarre & 35.0 & 5,692 & 5,243 \\
Basque Country & 20.8 & 6,448 & 4,764 \\
\hline
\end{tabular}

Note: Public spending per student in non-university education, (occupational training is excluded). The student unit has been transformed into a full-time equivalent, according to the methodology used in international statistics aproaches. The 2013-2014 academic year is the last one for which consolidated data is available.

Source: Authors' own work using the data provided by Las cifras de la educación en España. Curso 2014-2015 (Edición 2017). Ministerio de Educación, Cultura y Deporte.

\section{Harmonised student academic performance, by autonomous community}

For the purpose of measuring student academic performance, as the main output of the system, this study has considered the average scores obtained in PISA 2015 in the tests corresponding to the three traditional areas of literacy, mathematics and science (using the 10 plausible values in the estimation of the performance measurement average). The relatively strong link - depending on the countries - between students' socio-economic status and school outcomes forces us to subtract the influence of this variable on student results as an essential step in contextualisation 
16 before conducting a reasonably standard comparison of country outputs and, in our case, autonomous communities.

\subsection{Academic performance vs. ESCS by autonomous community}

A linear regression analysis between academic performance measured with an arithmetic average of scores obtained in the PISA 2015 tests, in the three areas abovementioned, and ESCS in the various Spanish autonomous communities, showed the importance of this relationship in Spain when the autonomous community is used as the analysis unit. Of note is the considerable size of the $R^{2}$ determination coefficient $(0.66)$ (statistical significance $<0.01$ ). That is, $66 \%$ of the variance of the results obtained in PISA 2015 by the autonomous communities can be explained by the socio-economic and cultural status index. This confirms the need, in this case, of correcting the influence of this variable on school performance when comparing the results of the autonomous communities in a reasonably standard manner.

Therefore, and in order to put the results in context, we corrected the PISA scores according to ESCS based on the 'gradient' method used by the OECD. Application of this methodology to the case in hand meant conducting 72 secondary analyses of student microdata: for all of Spain, for each one of the 17 autonomous communities, and for each score obtained in the 3 major areas of PISA 2015 (science, literacy, and mathematics), as well as for the overall score.

The scattered plots shown in Figure 2 indicate the overall behaviour of the two variables of interest (performance in each subject and ESCS) where each student is represented as a dot on the plane defined by their scores in both variables. This makes it possible to see the positive relationship that exists between them, which is emphasised by the best fit line for the point cloud, as well as determining the value of the ordinate at the origin indicating the corresponding corrected score for the ESCS effect.

\subsection{Comparison of harmonised PISA results by autonomous community}

The analysis of the association between ESCS and overall performance in PISA 2015 for Spain and all of the autonomous communities shows a positive relationship and statistically significant in all cases, with an $R^{2}$ strength that ranges between 0.19 points in the case of Murcia and 0.07 in Galicia; Asturias and the Community of Madrid follow Murcia with 0.19 and 0.17, respectively. At the opposite end are Castile and Leon and the Basque Country, with values around 0.09. Table 2 shows, in comparative terms for the various autonomous communities, the gross values of overall average scores obtained in PISA 2015 and corrected values, following the PISA methodology for correcting the ESCS effect.

From the analysis in Table 2, significant differences were found among the autonomous communities, with the highest value between Castile and Leon and the 
Sciences

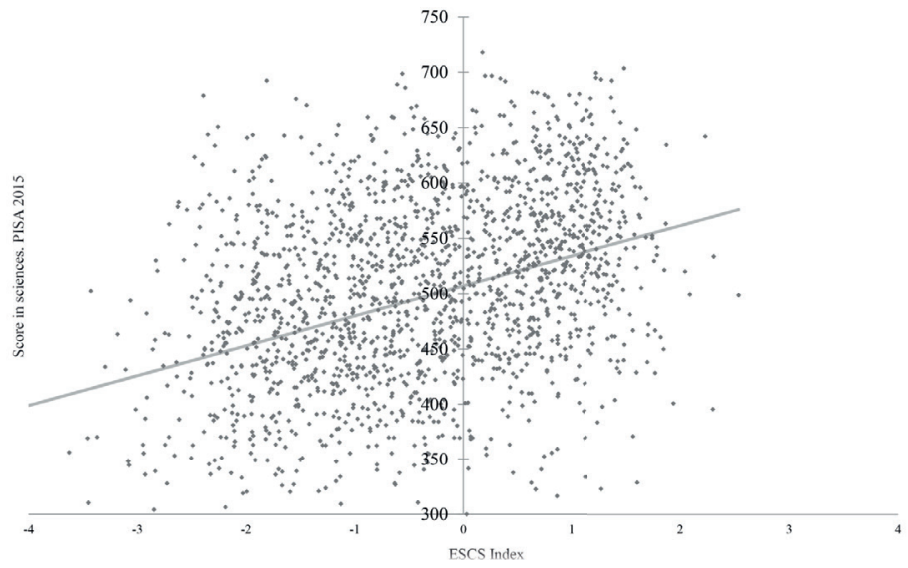

Math

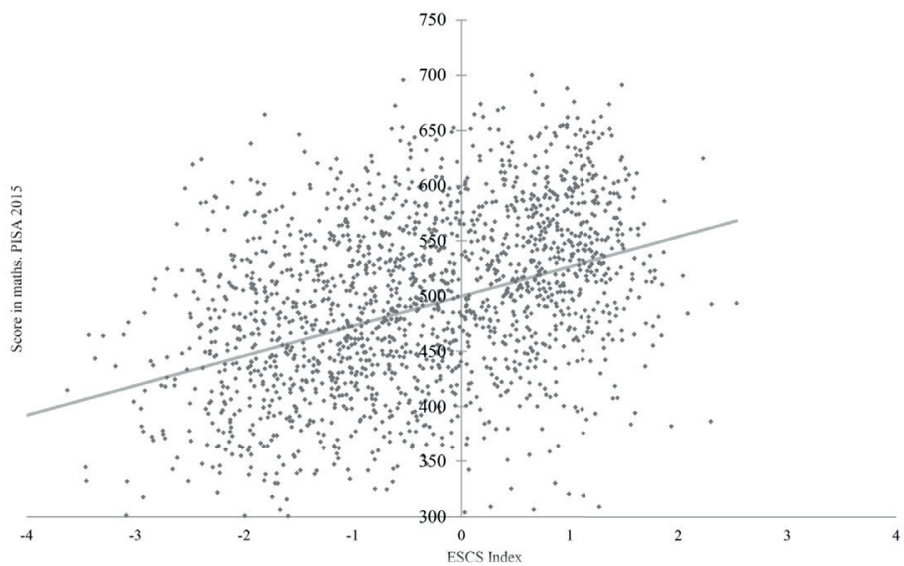

\section{Reading}

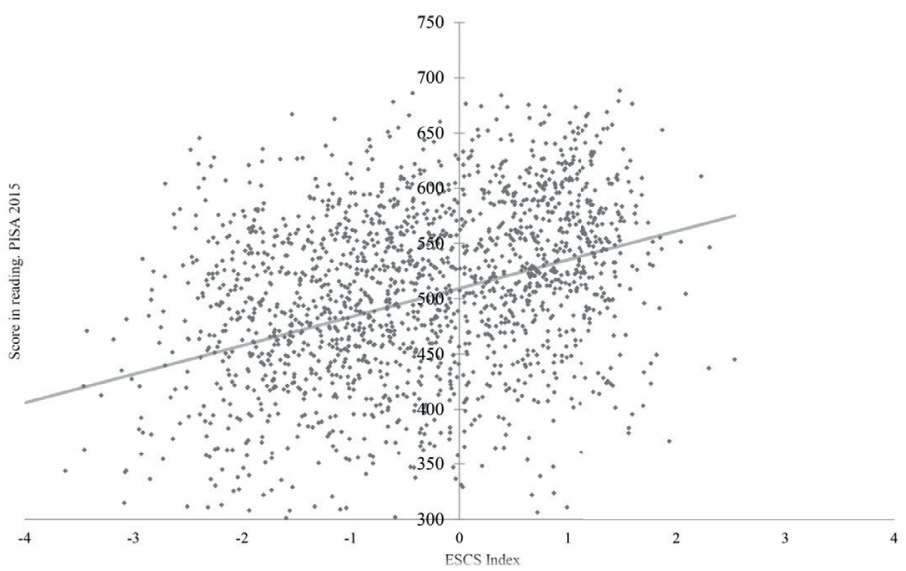

Figure 2 PISA 2015 results vs. student socio-economic and cultural status (ESCS) index in Spain. Source: Authors' own work based on PISA 2015 microdata. 
18 Canary Islands: 32 PISA points, after correcting for the socio-economic and cultural status effect, which corresponds to approximately an average academic delay of one year between those autonomous communities.

Table 2 Gross values of overall average scores obtained in PISA 2015 and corrected values according to ESCS impact.

\begin{tabular}{lccc}
\hline & $\begin{array}{c}\text { Socio-economic } \\
\text { and cultural status }\end{array}$ & \multicolumn{2}{c}{ Average scores obtained in PISA 2015 } \\
\cline { 3 - 4 } (ESCS) index & Gross values & Corrected values \\
\hline Spain & -0.51 & 491 & 505 \\
Andalusia & -0.87 & 473 & 496 \\
Aragon & -0.39 & 505 & 516 \\
Asturias & -0.42 & 497 & 510 \\
Balearic Islands & -0.65 & 482 & 498 \\
Canary Islands & -0.8 & 470 & 492 \\
Cantabria & -0.43 & 497 & 508 \\
Castilla-León & -0.44 & 516 & 525 \\
Castilla-La Mancha & -0.66 & 494 & 510 \\
Catalonia & -0.35 & 501 & 511 \\
Community of Valencia & -0.53 & 493 & 506 \\
Extremadura & -0.79 & 474 & 494 \\
Galicia & -0.52 & 505 & 515 \\
La Rioja & -0.46 & 498 & 511 \\
Community of Madrid & -0.1 & 513 & 516 \\
Murcia & -0.82 & 480 & 503 \\
Navarre & -0.32 & 515 & 523 \\
Basque Country & -0.25 & 489 & 495 \\
\hline
\end{tabular}

Source: Authors' own work based on PISA 2015 microdata.

\section{Efficiency of public spending on education per student in Autonomous Communities}

According to the notion of efficiency or productivity, Table 3 shows the values of this variable that are the result of considering harmonised input and output values; values which were previously shown in Tables 1 and 2, respectively. Each figure represents the euro cost of each PISA point in each autonomous community. Figure 3 is a graphic representation of the deviations of efficiency values in public spending on education per student compared to the Spanish average of the various Autonomous Communities. 
Table 3 Efficiency values of public spending per student by autonomous community.

\begin{tabular}{lc}
\hline & Efficiency (PISA point /euro) \\
\hline Spain & 0.108 \\
Andalusia & 0.108 \\
Aragon & 0.107 \\
Asturias & 0.099 \\
Balearic Islands & 0.111 \\
Canary Islands & 0.114 \\
Cantabria & 0.101 \\
Castilla-León & 0.105 \\
Castilla-La Mancha & 0.099 \\
Catalonia & 0.111 \\
Community of Valencia & 0.112 \\
Extremadura & 0.091 \\
Galicia & 0.091 \\
La Rioja & 0.102 \\
Community of Madrid & 0.121 \\
Murcia & 0.102 \\
Navarre & 0.100 \\
Basque Country & 0.104 \\
\hline
\end{tabular}

Source: Authors' own work.

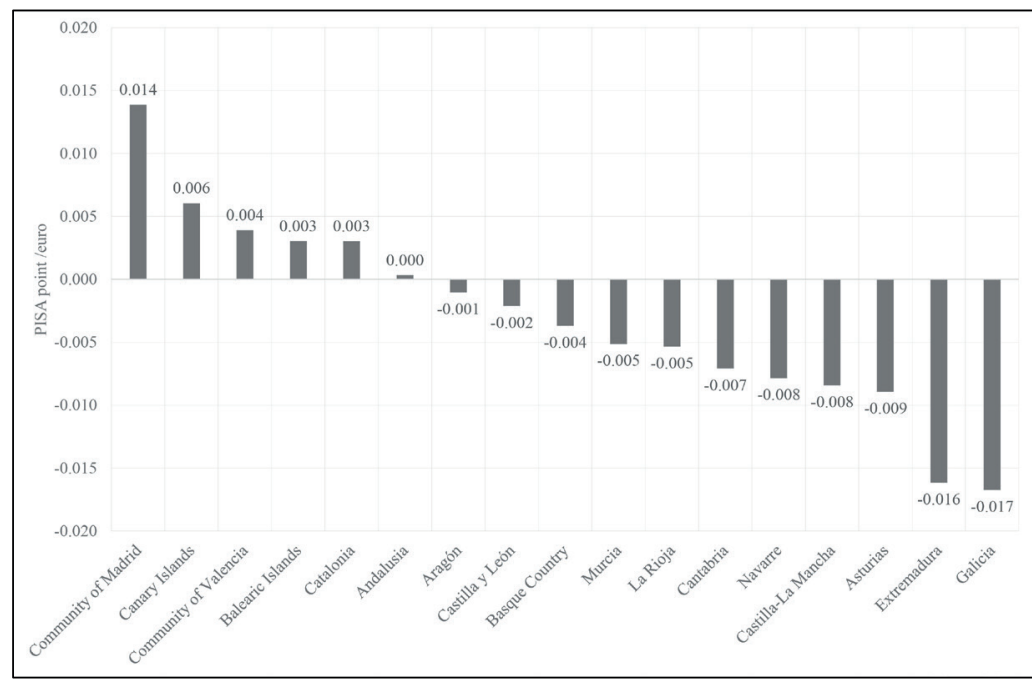

Figure 3 Deviations of efficiency values in public spending on education per student compared to the Spanish average by autonomous community.

Source: Authors' own work. 
Negative deviations of the autonomous communities with efficiency values below the Spanish average show efficiency gain margins by most of them regarding the modest objective of being equal, at least, to that average. When results versus expenditure are shown on a chart and the corresponding regression analysis is carried out, the statistical relationship is very weak $\left(R^{2}=0.09\right)$ and not significant $(0.21)$, which indicates the heterogeneous impact of different factors on the efficiency of the various autonomous communities. Figure 3 shows this dispersion and recommends organising the autonomous community positions in quadrants in the inputs-outputs chart. Without prejudice to the subsequent analyses, it is worth examining the 'quadrant analysis' with special attention on the 'optimal quadrant' low expenditure and high results - and the 'worst quadrant' - high expenditure and low results - in relation to the average values of the two variables considered. The first group would include, although in distant positions, the Community of Madrid, Catalonia, and the Community of Valencia; and in the second one, Murcia, the Basque Country, and Extremadura.

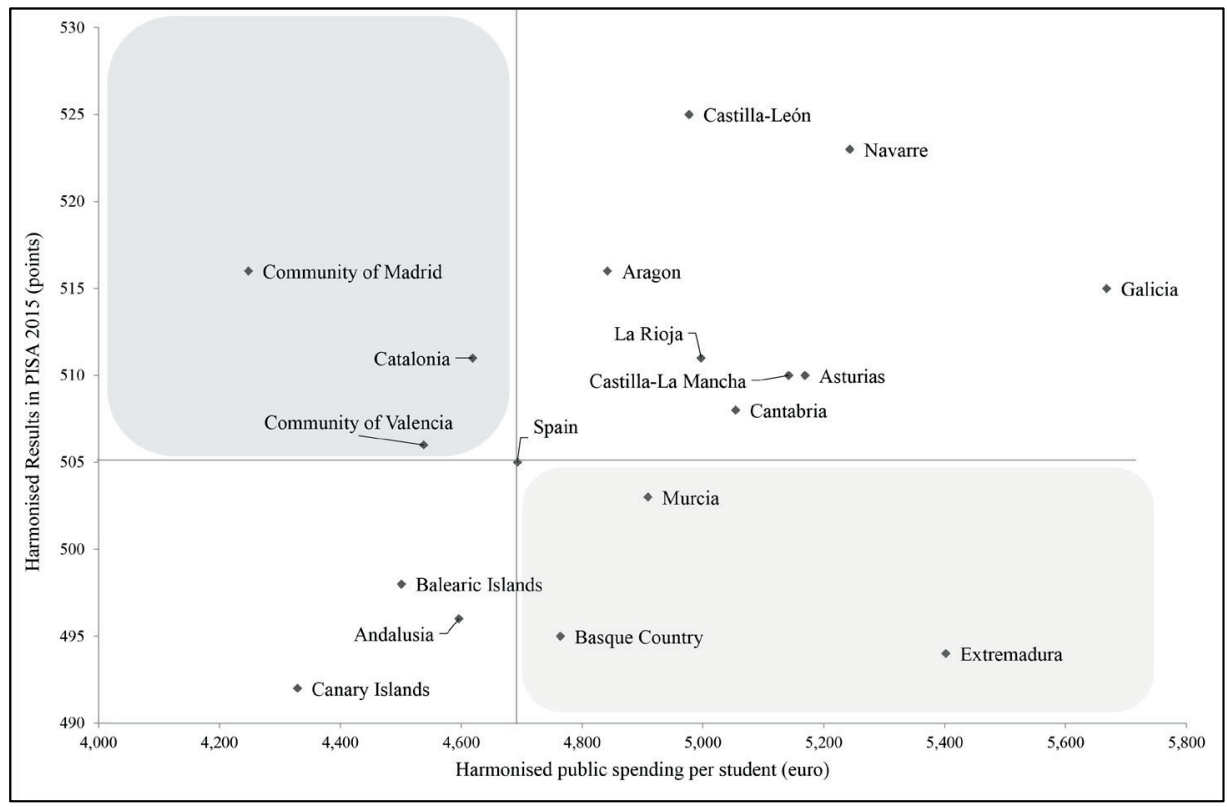

Figure 4 PISA 2015 Results vs. public spending per student and class, both harmonised, by autonomous community.

Source: Authors' own work. 


\section{Public spending on education vs. levels of wealth and effectiveness vs. spending efficiency}

The previous analyses provide a very diverse picture of behaviours in the autonomous communities, both regarding expenditure and results, which recommends searching for clearer and more useful diagnoses in order to direct policy. The aim, after all, and in light of the resulting situation map, is to come up with recommendations for education spending in Spain, as well as for other policies.

\subsection{Public spending on education vs. levels of wealth}

The first step in this direction would be to include the level of wealth of the autonomous communities in the analyses. This would be justified for two reasons: first, because, as mentioned in the introduction, the impact of the expenditure variable on student outcomes depends on the degree of development of the countries - or economic units - which is reflected in the scale of their spending on education; and second, because, considering the widely recognised role of education and training as drivers of economic and social progress in the medium and long-term, the less wealthy autonomous communities should make an effort to spend more than the average on education per student.

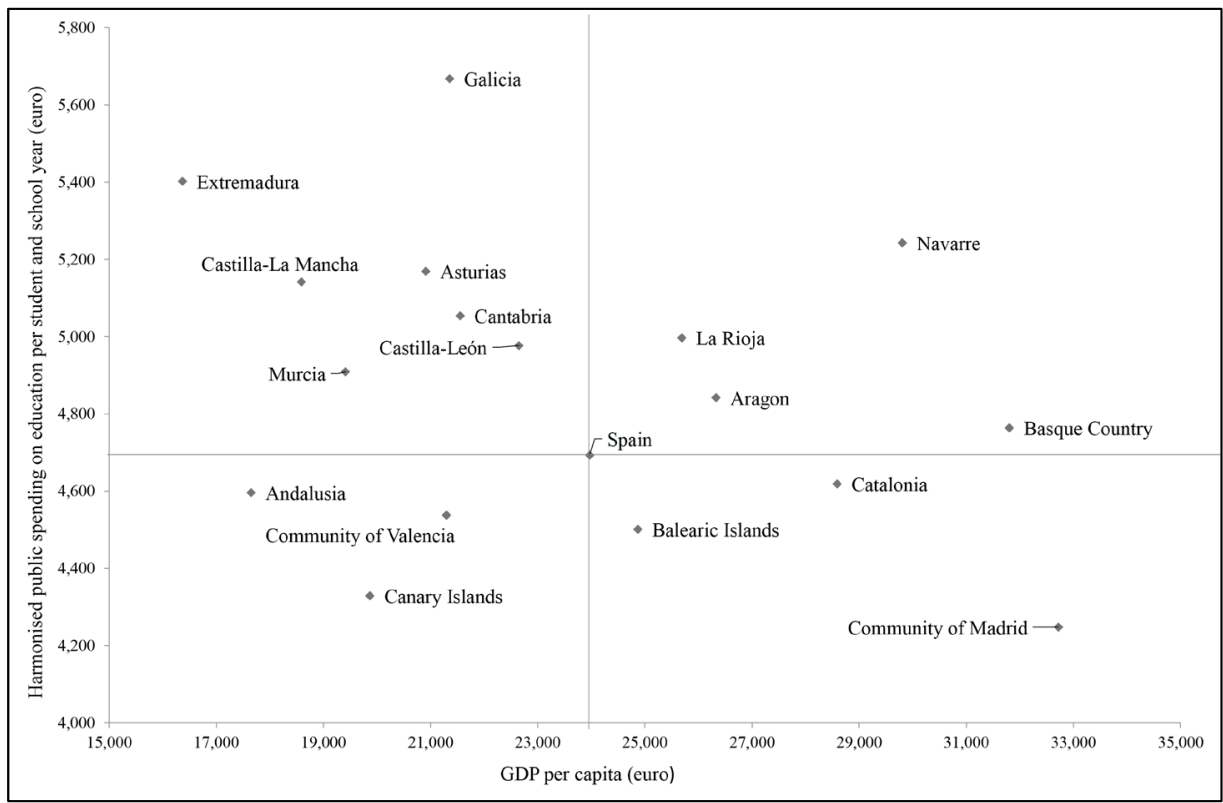

Figure 5 Harmonised public spending on education per student vs. level of wealth by autonomous community.

Source: Authors' own work. 
Figure 5 shows the values of public spending on education per student versus wealth levels measured according to GDP per capita for all of the autonomous communities. The resulting point cloud evidences significant dispersion. This leads to the parameters resulting from the regression analysis and corresponding to ANOVA $\left(R^{2}=0.10 ;\right.$ sig 0.19$)$. The above notwithstanding, the quadrant analysis provides information of great interest. When we look at the autonomous communities with below average wealth level, we find, again, heterogeneous performance. Thus, the Canary Islands, the Community of Valencia, and Andalusia, with a wealth level below average, spend less than the Spanish average; while Murcia, Castile-Leon, Cantabria, Castile-La Mancha, Asturias, Extremadura, and Galicia spend more than average. Therefore, $70 \%$ of the less rich autonomous communities are investing considerably in education through their spending policies.

\subsection{Spending effectiveness vs. efficiency}

Even when education spending aligned with population needs is a necessary condition to achieve good academic outcomes, it is not nearly enough. This is where the quality of the policies and their degree of efficiency to shape the well-known desideratum of 'spending better' comes in. It would therefore be advisable to follow this in the analyses and fill out the map above considering the effects of the other

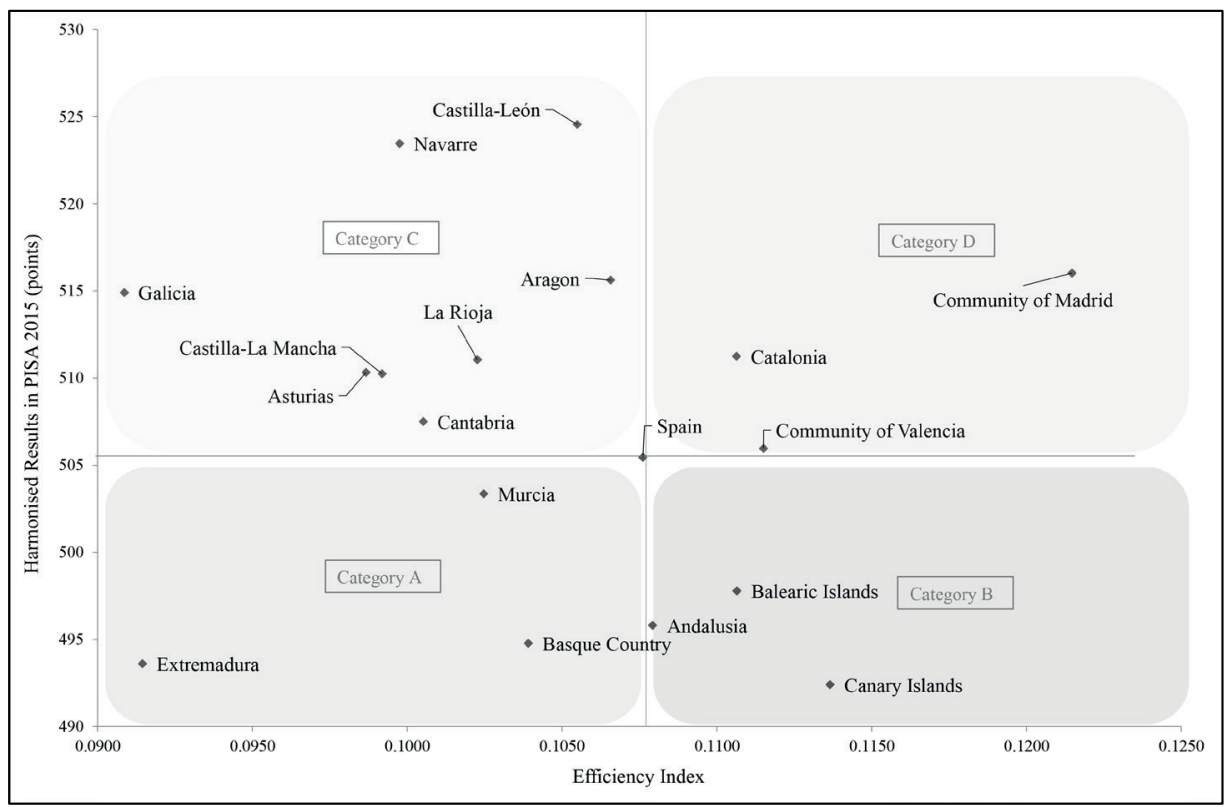

Figure 6 Effectiveness, measured by the average scores in PISA 2015, corrected for the ESCS effect, vs. the values of efficiency of public spending on education by autonomous communities. Source: Authors' own work. 
policies not related to expenditure. Figure 6 shows effectiveness values, measured by the PISA 2015 scores obtained in the various communities after correcting for the effect of ESCS versus the corresponding values of efficiency.

Again, we see a notable dispersion in the point cloud $\left(R^{2}=0.003 ;\right.$ sig 0.82$)$. Nonetheless, it is possible to divide the various autonomous communities into four classes: those not very effective and not very efficient (Category $A$ ); those not very effective but efficient (Category B); those effective but not very efficient (Category C); and finally, those effective and efficient (Category D).

Notwithstanding the above analyses, it should be noted that efficiency, as a feature of governance quality, is not a value in itself if not accompanied by the aspiration for equity. This dimension of our diagnosis, which is not minor, is examined in depth below.

\section{Education equity in the autonomous communities}

Without prejudice to that constitutional ideal of equal right to quality education across the country, which we shall refer to below, it is necessary to examine, empirically, the issue of equity within each autonomous community, as well as the existing differences between them and the corresponding consequences. All of this with the aim of implementing corrective policies, including spending policies, both at the state and autonomous community levels and in line with their respective responsibilities.

\subsection{Two different and complementary approaches to the degree of equity in the education system}

The two parameters of the statistical relationship between ESCS and PISA scores impact and intensity - facilitate, as mentioned above, different and complementary approaches to the degree of equity in an education system. PISA 2015 provides direct data on these two variables - socio-economic and cultural status and academic performance - for the countries and economies participating in the programme. Furthermore, their rich micro database allows one to determine the two relationship parameters abovementioned, through secondary analyses for the regions of those countries that have participated with a broader, statistically representative sample of these geographical areas. This would be the case of Spain, as shown in Section 4. Secondary empirical analyses, described above, have helped us determine the two parameters related to equity in the education system: the m slope of the regression lines, shown in Figure 3, and the $R^{2}$ coefficient of determination of the corresponding analyses. The values of both parameters are shown in Table 4. 
24 Table 4 Impact magnitude values $(\mathrm{m})$ of ESCS on academic performance, based on average scores in the three PISA 2015 tests, and the intensity of the corresponding ratio $\left(R^{2}\right)$ by autonomous community.

\begin{tabular}{lll}
\hline & Intensity $\left(R^{2}\right)$ & Impact $(m)$ \\
\hline Spain & 0.16 & 26.62 \\
Andalusia & 0.16 & 26.36 \\
Aragon & 0.14 & 26.56 \\
Asturias & 0.19 & 30.01 \\
Balearic Islands & 0.11 & 23.96 \\
Canary Islands & 0.15 & 27.05 \\
Cantabria & 0.11 & 23.88 \\
Castilla-León & 0.09 & 19.83 \\
Castilla-La Mancha & 0.14 & 23.59 \\
Catalonia & 0.16 & 27.52 \\
Community of Valencia & 0.14 & 23.96 \\
Extremadura & 0.13 & 24.01 \\
Galicia & 0.07 & 18.69 \\
La Rioja & 0.15 & 27.15 \\
Community of Madrid & 0.17 & 27.53 \\
Murcia & 0.19 & 28.07 \\
Navarre & 0.15 & 26.41 \\
Basque Country & 0.09 & 21.36 \\
\hline
\end{tabular}

Source: Authors' own work.

As pointed out by the OECD, in relation to PISA 2015 (OECD, 2016), "While these two measures are positively correlated, they capture different aspects of the relationship between students' performance and socio-economic status, with potentially different policy" (p. 217). The preceding contributions, regarding implications (Willms, 2006; OECD, 2013), are in this case of utmost interest to prepare evidence-based recommendations on the most appropriate type of education policies for the various autonomous communities.

\subsection{Analysis of the seventeen autonomous communities}

In light of the above, we should identify the position of the various Spanish autonomous communities in an impact magnitude versus intensity of the relationship chart and in accordance with a quadrant chart defined according to the national averages of these two parameters. Figure 7shows the distribution of the seventeen 


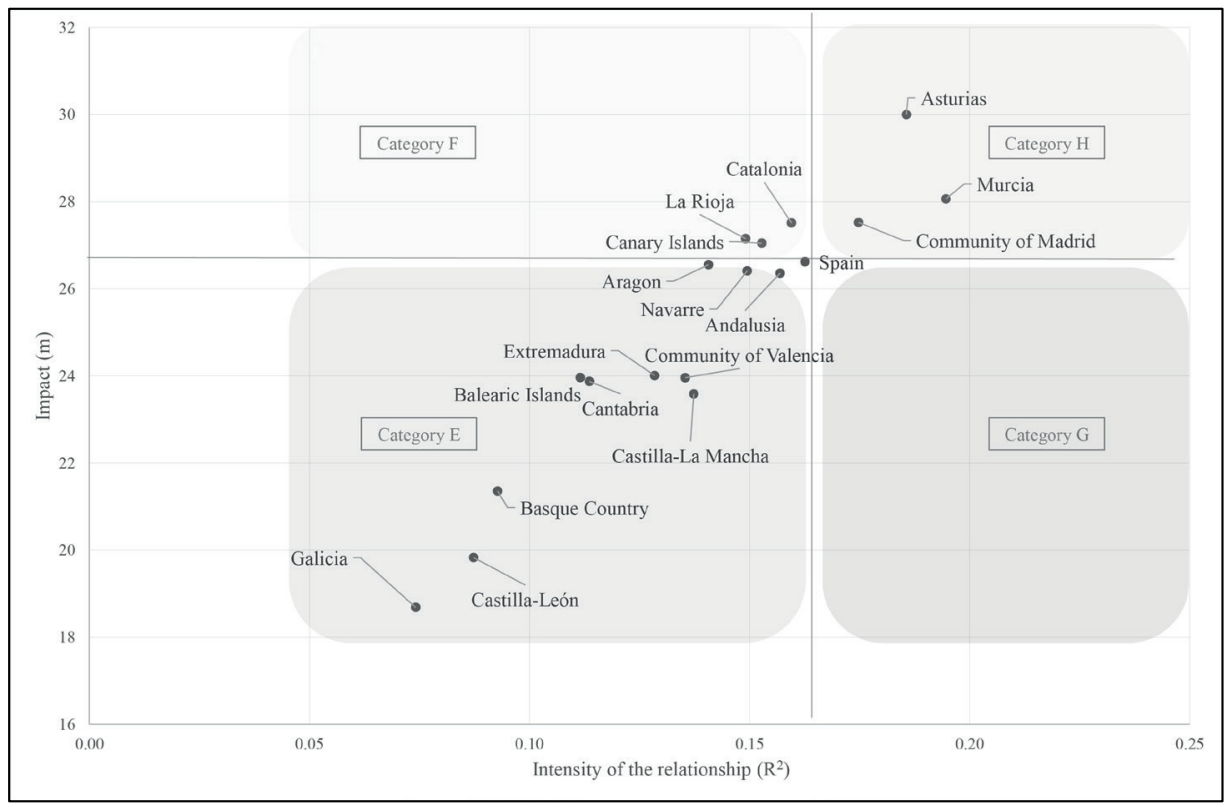

Figure 7 Distribution of the seventeen autonomous communities in the four categories according to the values of the two parameters - impact $(m)$ and intensity of the relationship $\left(R^{2}\right)$ of education equity.

Source: Authors' own work.

autonomous communities in the four quadrants of the chart, each one identified with the corresponding category: Category E (weak impact, weak intensity), Category F (strong impact, weak intensity), Category $G$ (weak impact, strong intensity) and Category $\mathrm{H}$.

\subsection{Efficiency and equity}

There is broad consensus among developed societies that, while efficient management of public resources is a characteristic of good governance, the administration of public spending cannot turn its back on the need for equity. For this reason, it was pertinent to supplement the above bivariate analyses on Spanish autonomous communities with another similar one that considered their positioning in an efficiency versus equity chart. In this case, we measured efficiency of spending on education as the efficiency index calculated previously, and as a reverse indicator of the degree of education equity, the impact magnitude $(\mathrm{m})$ of the socio-economic and cultural (ESCS) status on school performance based on the average score obtained in the three core PISA tests. 
26 Table 5 Impact values $(m)$ of ESCS on PISA 2015 performance, and the efficiency index by autonomous community.

\begin{tabular}{lcc}
\hline & Impact $(m)$ & Efficiency (PISA point/euro) \\
\hline Spain & 26.62 & 0.1076 \\
Andalusia & 26.36 & 0.1079 \\
Aragon & 26.56 & 0.1066 \\
Asturias & 30.01 & 0.0987 \\
Balearic Islands & 23.96 & 0.1106 \\
Canary Islands & 27.05 & 0.1137 \\
Cantabria & 23.88 & 0.1005 \\
Castilla-León & 19.83 & 0.1055 \\
Castilla-La Mancha & 23.59 & 0.0992 \\
Catalonia & 27.52 & 0.1106 \\
Community of Valencia & 23.96 & 0.1115 \\
Extremadura & 24.01 & 0.0914 \\
Galicia & 18.69 & 0.0909 \\
La Rioja & 27.15 & 0.1023 \\
Community of Madrid & 27.53 & 0.1215 \\
Murcia & 28.07 & 0.1025 \\
Navarre & 26.41 & 0.0998 \\
Basque Country & 21.36 & 0.1039 \\
\hline
\end{tabular}

Source: Authors' own work.

Table 5 shows the results corresponding to each autonomous community. A linear regression analysis of the two variables indicates a statistically weak and not significant relationship between them $\left(R^{2}=0.13\right.$; sig 0.15$)$. The notable dispersion of the point cloud is not compatible with a sufficiently established causation ratio between the two variables, so there is no type of determinism that makes efficiency and equity two irreconcilable factors. The challenge, both for autonomous communities and for the state, is to make the two factors compatible and not opposing. This shall undoubtedly depend on the appropriateness of the definition and implementation of education policies, including those related to spending.

Four categories corresponding to the respective quadrants of the chart in Figure 8 can be identified: Category I (low impact, low efficiency), Category J (high impact, low efficiency), comprising the so-called 'worst quadrant' as it groups inefficient and low equity behaviours, Category $\mathrm{K}$ (low impact, high efficiency), corresponding to the 'optimal quadrant', Category $L$ (high impact, low efficiency) with high levels of efficiency and their good, or relatively good, performance outcomes, and finally Category I (low impact, low efficiency), which is the most populated one, including 8 autonomous communities. This is the predominant category in the country as it 


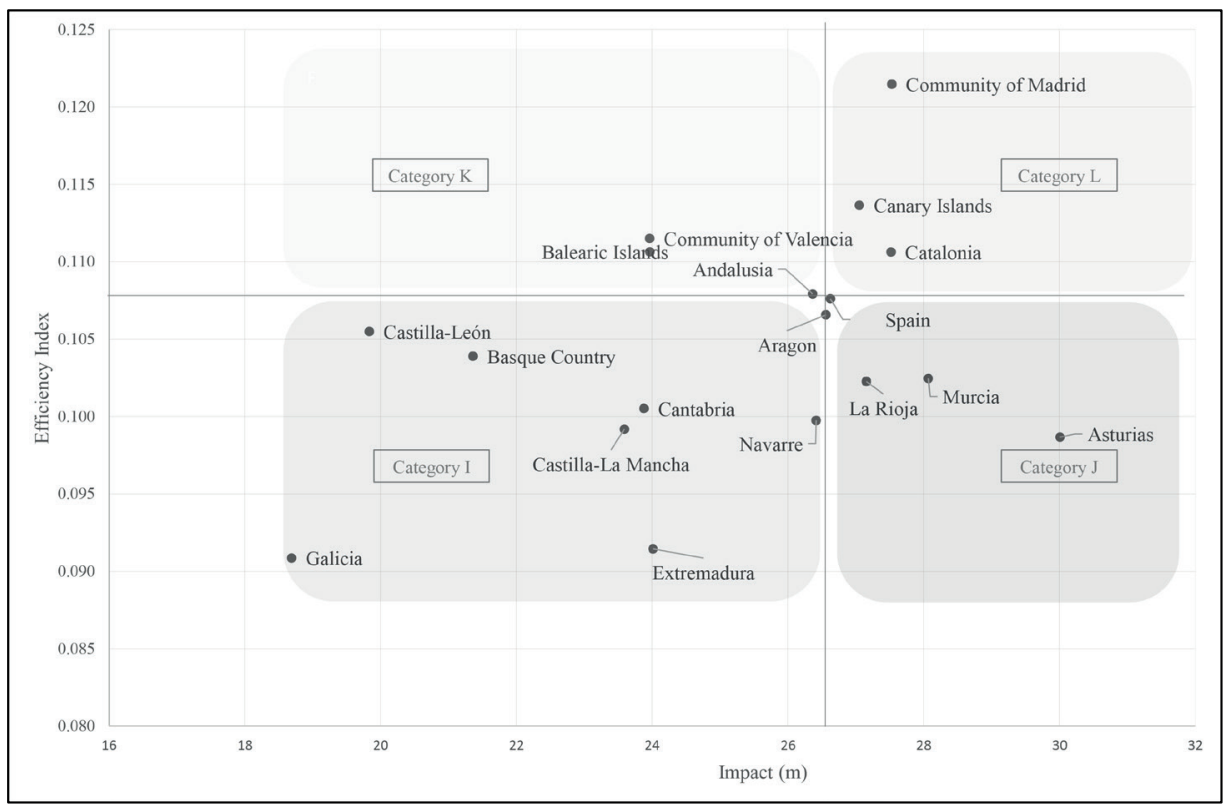

Figure 8 Efficiency vs. equity for the seventeen Spanish autonomous communities.

Source: Authors' own work.

groups almost half of the 17 autonomous communities in which there is a level of equity that is higher than average, accompanied, nonetheless, by a level of spending efficiency that is lower than average.

\section{Discussion}

One of the issues that has emerged from the analyses of the data in this study is the considerable dispersion of the point cloud in the inputs versus outputs charts. Unlike the acknowledgement made by UNESCO in 2004, or the comments repeated by the OECD, in this same sense on the PISA data and described above, this notable dispersion of the point cloud in the case of the seventeen Spanish autonomous communities poses a problem when it comes to identify, even approximately, the spending threshold below which the magnitude of resources could have a significant impact on outcomes in Spain. Determining this threshold would, to a certain extent, have allowed clarifying actions of the public administrations in this regard and, in particular, the actions by the state to effectively ensure real equal opportunities among Spanish students, regardless of the autonomous community in which they live.

The OECD, using cumulative spending per student aged 6 to 15 as an input indicator, set this threshold at US $\$ 50,000$ (PPP). In comparison, Spain, as a whole, with an amount of US $\$ 74,947$ (PPP), is significantly above the threshold (OECD, 2016). This leads one to think that, in spite of the existing differences between the autonomous 
28 communities regarding spending on education, they are all above the threshold figure. However, from the standpoint of assurance of the constitutional principle of equal opportunities, the problem of the source of the differences in school outcomes among the autonomous communities still stands, without being able to completely rule out the possibility that funding differences is one of the variables, internal to the Spanish education system, which could be having, among others, a statistically significant impact on these differences in academic performance. Various studies have previously addressed the problem of the determining factors of the differences in education performance in Spain (Villar, 2012). Beyond the influence of certainly different regional socio-economic levels, which could be harmonised with statistical procedures as we did in this study, those papers gave rise to certain factors related to policies - preschool education, school characteristics, etc. However, a substantial part of the differences found cannot be attributed to any of the explanatory variables considered.

At this point, we should note the limitations there may be in the spending efficiency values calculated in this paper, which are partly due to the relatively diffuse variables involved, that is, not apparently linked to the policies, such as cultural guidelines or level of social involvement, but which, nonetheless, have an impact on outcomes. We are considering here education policy in a broad sense, which includes the explicit definition of the goals of the reforms and their priorities (the actual 'policies'), formulation of strategies to achieve those goals, and specific plans for their implementation (Mingat, Tan, \& Sosale, 2003). These cultural guidelines are based on family and social values that have an impact not only on the confined family setting, but also on school culture, on peer interactions and on school climate. This contributes to creating a social atmosphere, in general, that favours academic success while at the same time generated by it in a kind of virtuous cycle. This social mechanism is not necessarily linked to the level of wealth of the corresponding autonomous community but rather to the nature and strength of its alignment with the shared values that are conducive to academic achievement (Méndez, Zamarro, García, \& Hitt, 2015). The role of the so-called 'non-cognitive skills' which, as pointed out elsewhere, are strongly linked to the world of attitudes and the area of values (López Rupérez \& García, 2017), has proven to be pertinent in order to explain differences in academic performance between autonomous communities. Thus, the study by Méndez et al. (2015) estimated that the reduction of the standard deviation in the differences found in non-cognitive skills linked to academic performance leads to a reduction of approximately $25 \%$ of the differences found among autonomous communities regarding their average scores in the PISA tests. Another factor related to school climate and culture, as a set of shared standards and values, is the interaction among students (peer effects), for which Hattie (2003), based on meta-analytical syntheses, estimated it explained between $5 \%$ and $10 \%$ of the performance differences among students.

According to the above, those autonomous communities that have this valuable collective capital, with equal spending on education, will be more effective and 
probably more efficient. Upon careful consideration of the remaining policies other than those of expenditure, we should now consider whether it would be possible to operate in that area of classic virtues, values, and attitudes at the level of the autonomous communities and also at the state level regarding their responsibility for providing equal and basic conditions for school achievement. The answer is definitely in the affirmative (López Rupérez \& García, 2017), therefore it cannot be discarded that significant explanation for interregional variance in school outcomes is associated with these policies unrelated to spending. For example, the introduction of the so-called 'character education' in the school syllabus, as proposed by the Center for Curriculum Redesign (Fadel, Bialik, \& Triling, 2015) and contemplated later by the OECD's BIAC (BIAC, 2016), ratifies the above. Stressing these types of policies must be one of the goals of quality education governance. In other words, the absence or omission of these policies is an intrinsic source of inefficiency whose impact is probably embedded in the data of the quadrant chart in Figure 4 and the subsequent analyses. At an international level, a relatively intense relationship has been identified between resilience - as a recognised non-cognitive skill - and performance in PISA 2015 in the set of participating countries (López Rupérez \& García, 2017). With an $R^{2}$ determination coefficient of 0.76 , the study reveals both the strength of this relationship as well as the privileged position of some Eastern countries, even those with a lower level of development, a position that is most likely linked to the education philosophy of those societies and the shared code of values in their schools (Stevenson \& Stigler, 1992).

One of the global results revealed in this study is the remarkable territorial inequality which, both in inputs or resources, and outputs or outcomes, comprises the Spanish territorial landscape. This inequality implicitly alludes to the conditions under which citizens enjoy the fundamental right to education, and its correction concerns the state prima facie, one of its exclusive responsibilities pursuant to Article 149.1.1 of the Spanish Constitution, being, "Regulation of the basic conditions that guarantee equality among all Spanish citizens to exercise their rights and compliance with constitutional obligations."

The reasoning and evidence provided by this study give rise to the appropriateness of a twofold action in this area: one on the side of inputs that allows increasing resources wherever it is objectively necessary, due to the low level of spending on education, due to the lower level of wealth, or due to the notably lower results; and another one on the side of outputs, acting upon procedures in order to help increase school results through improvement of education governance quality. With this two-pronged approach, actions both by the central government and the regional governments must be coordinated, loyal, and smart. A provision of extraordinary funds by the state must be earmarked, as a priority, for those autonomous communities which, in spite of their lower level of wealth, devote above average amounts of resources and yet obtain lower results. Establishing a strong bond between those extraordinary funds from the state and an improvement in processes, monitoring policies, their evaluation and results, is an essential procedure to ensure efficient 
30 use of these additional resources. Equally important is support from the Ministry of Education, through plans agreed upon with the regional education authorities, in the form of assistance for diagnosis, orientation, international consulting, etc., in those autonomous communities that, in light of their results, require and request them, which will provide knowledge and competences and will contribute to the success of education improvement plans which can no longer be delayed.

\section{Conclusions and recommendations}

Effectiveness, efficiency, and equity are three factors of education systems that can be measured with a secondary analysis of PISA 2015, alluding to other characteristic features of governance quality. This study provides new data and original diagnosis analysis related to each one of the seventeen Spanish autonomous communities. Below is a set of conclusions summarising the essential findings of the study and providing recommendations, in line with those findings, for each one of the autonomous communities based on their position in relation to national averages in each one of the three factors that are characteristic of advanced education systems. The aim is to provide public authorities with grounded guidance aimed at facilitating their intervention in the Spanish education system upon an empirical base.

\subsection{Conclusions}

From the empirical data and the analyses generated in this study, we can draw the following conclusions, summarised as follows:

a) Regional distribution of spending on education per student shows considerable differences among autonomous communities, which together with the proven non-linear relationship between spending per student and academic performance established in international analyses, opens the door to the possibility of improving outcomes through a different treatment of the autonomous communities regarding spending on education with efficiency criteria.

b) The existence of significant differences among autonomous communities regarding the level of rurality of their school systems, with actual impact on the average cost of the school place supported with public funds, requires, for the purpose of comparison, empirical territorial harmonisation actions on public spending on education per student.

c) The known influence of the socio-economic and cultural status (ESCS) of students on academic performance makes it necessary to control said influence in order to ensure that the comparison of autonomous communities is relatively homogeneous.

d) In line with the systemic approach, efficiency of public spending on education of the various autonomous communities can be calculated as the quotient between the system output, measured with the average score in PISA 2015 corrected by ESCS, 
and its input, measured with public spending on education per student harmonised in relation to school rurality.

e) Representation of the positions of the seventeen autonomous communities in the chart of harmonised inputs-outputs leads to a point cloud with a considerable degree of dispersion, which indicates the existence of factors of a different nature that have an impact, heterogeneously, on the efficiency of the various autonomous communities. Unlike the case of international analyses conducted in this regard by UNESCO and the OECD, it is impossible to draw an efficiency curve that matches, in a statistically significant manner, those point cloud and, therefore, it is not possible to empirically determine, with this methodology, the threshold under which an increase in spending per student could result in an evident improvement in academic performance.

f) Notwithstanding the above conclusion, we conducted a quadrant analysis, based on national averages, with the following key results. In the 'optimal quadrant', related to efficiency (low expenditure and high outcomes), are Catalonia, the Community of Madrid, and the Community of Valencia. As for the 'worst quadrant' (high expenditure and low outcomes), it includes Extremadura, Murcia, and the Basque Country.

g) The empirical relationship between public spending on education per student and the level of wealth of an autonomous community, measured by GDP per capita, is not very clear. There are autonomous communities with a lower level of wealth that spend more than average and other richer ones that spend less than average.

h) When we look at the autonomous communities with a level of wealth that is below average, we find that Murcia, Castile-Leon, Cantabria, Castile-La Mancha, Asturias, Extremadura, and Galicia spend more than average after harmonising expenditure in line with the Rural Schooling Index. Therefore, $70 \%$ of the less rich autonomous communities are investing considerably in education through their spending policies.

i) The representation of the effectiveness values - measured by the PISA 2015 scores obtained in the various autonomous communities after correcting for the effect of ESCS - versus the corresponding values of efficiency allows us to group the 17 autonomous communities into four categories:

- Category A (low efficiency, low effectiveness) includes Murcia, Extremadura and the Basque Country. All of them are making a financial effort in favour of education which is greater than average, but this is not being reflected, at least at present, in the outcomes. This situation indicates a problem with processes and policies, that is, with governance.

- Category B (high efficiency, low effectiveness) includes Andalusia, Balearic Islands and the Canary Islands. The situation of these autonomous communities indicates a problem of insufficient funding that should be corrected either by the state or the community itself.

- Category C (low efficiency, high effectiveness) includes Galicia, Asturias, Castile-La Mancha, Navarre, Cantabria, La Rioja, Castile-Leon, and Aragon. These 
communities spend more than average to obtain higher than average results but with an efficiency that is lower than average. In these cases, efficiency should be improved with a 'focus on outputs', which means operating on the processes in order to spend available resources better.

- Category D (high efficiency, high effectiveness) includes the autonomous communities that are effective and efficient. This is the case of Catalonia, the Community of Valencia and the Community of Madrid. The above notwithstanding, it is necessary to remember that efficiency is not an acceptable value if it occurs at the expense of equity.

j) Representation of the values of the autonomous communities in an efficiency versus equity chart allowed grouping the 17 autonomous communities into four categories:

- Category I (low equity, low efficiency), groups the autonomous communities of Asturias, La Rioja and Murcia. Priority actions should focus both on improving the outcomes of all and on serving socially disadvantaged environments.

- Category J (high equity, low efficiency) is the most populated one, including 8 autonomous communities (Aragon, Cantabria, Castile and Leon, Castile-La Mancha, Galicia, Extremadura, Navarra, and Basque Country). The challenge for this category is then to improve its efficiency without reducing its equity level, which must be done by either improving outcomes without reducing spending or increasing both but in a way that the rise in outputs is greater than that in inputs.

- Category K (low equity, high efficiency) is occupied by the Canary Islands, Catalonia and the Community of Madrid which, in spite of their high, or relatively high, efficiency in public spending on education, show equity level levels lower than average. Given their high levels of efficiency and their good, or relatively good, performance outcomes, Catalonia and the Community of Madrid have the necessary conditions to prioritise equity policies. This is not the case of the Canary Islands, whose high levels of efficiency stem from very limited spending on education combined with low academic outcomes, as in the case of the Balearic Islands and Andalusia.

- Category L (high equity, high efficiency), includes the Balearic Islands, the Community of Valencia and Andalusia. The presence of these three communities in this category does not imply ignoring any improvement initiative given that their PISA results show noticeable progress, particularly in the Balearic Islands and Andalusia.

\subsection{Recommendations}

Based on the empirical evidence summarised in the conclusions section, below are a series of recommendations on how to direct policies for improving education in each one of the seventeen autonomous communities included in Table 6, with details on their characteristic traits regarding effectiveness, efficiency, and equity. 
Table 6 A synopsis of the recommended educational policies based on the empirical diagnosis of work.

\begin{tabular}{|c|c|c|c|c|}
\hline $\begin{array}{l}\text { Autonomous } \\
\text { Communities }\end{array}$ & 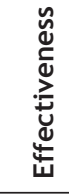 & 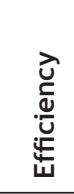 & 窎 & Recommendations \\
\hline $\begin{array}{l}\text { Community of } \\
\text { Valencia }\end{array}$ & + & + & + & $\begin{array}{l}\text { Despite the positive assessment in the three factors } \\
\text { considered, the results obtained in PISA show that } \\
\text { this Autonomous Community still has room to improve } \\
\text { efficiency compared to other. For this reason it would } \\
\text { be advisable to pay attention to the educational } \\
\text { policies of a general nature, described above and } \\
\text { aimed at raising the level of performance of all } \\
\text { students. }\end{array}$ \\
\hline $\begin{array}{l}\text { Catalonia } \\
\text { Community of } \\
\text { Madrid }\end{array}$ & + & + & - & $\begin{array}{l}\text { Because of its high efficiency levels and good, } \\
\text { or relatively good, performance results, these } \\
\text { Communities have the necessary conditions to } \\
\text { prioritize compensatory policies such as those } \\
\text { described above, focusing particularly on helping } \\
\text { students of modest status to obtain better results. }\end{array}$ \\
\hline $\begin{array}{l}\text { Aragón } \\
\text { Cantabria } \\
\text { Castilla-León } \\
\text { Castilla-La } \\
\text { Mancha } \\
\text { Galicia } \\
\text { Navarre }\end{array}$ & + & - & + & $\begin{array}{l}\text { Without reducing its level of equity, it is about } \\
\text { improving its efficiency, either by improving the } \\
\text { results without reducing the cost, or by increasing } \\
\text { both, but in such a way that the increase in outputs to } \\
\text { be greater than that of the inputs. For this, it would } \\
\text { be recommended to influence in the policies that have } \\
\text { the greatest impact on the results, particularly those } \\
\text { based on the teaching centers as preferential units of } \\
\text { action. }\end{array}$ \\
\hline $\begin{array}{l}\text { Andalusia } \\
\text { Balearic Islands }\end{array}$ & - & + & + & $\begin{array}{l}\text { Focus on educational policies of a general nature } \\
\text { designed to raise the level of performance of all } \\
\text { students, through interventions from the State (model } \\
\text { of the teaching profession, general management of } \\
\text { the curriculum, conception of school management, } \\
\text { etc.), and from the Autonomous Community (school } \\
\text { management, school climate, permanent teacher } \\
\text { training, stimulus system, complementary academic } \\
\text { organization, family-school relations, etc.). Develop } \\
\text { actions aimed at improving the non-cognitive abilities } \\
\text { of students. }\end{array}$ \\
\hline
\end{tabular}




Autonomous
Communities

\begin{tabular}{|c|c|c|c|c|}
\hline Canary Islands & - & + & - & $\begin{array}{l}\text { Undertake coordinated policies by the State and } \\
\text { Autonomous Community, both of a general nature } \\
\text { and specifically focused on disadvantaged sectors. } \\
\text { Mobilizing the material, human and knowledge } \\
\text { resources necessary to save these situations of } \\
\text { regional disadvantage. }\end{array}$ \\
\hline $\begin{array}{l}\text { Extremadura } \\
\text { Basque Country }\end{array}$ & - & - & + & $\begin{array}{l}\text { Focus on educational policies of a general nature } \\
\text { aimed at raising the level of performance of all } \\
\text { students, with criteria of efficiency, through } \\
\text { interventions of the State (model of the teaching } \\
\text { profession, general management of the curriculum, } \\
\text { conception of school management, etc.), and of the } \\
\text { Autonomous Community (management of the centers, } \\
\text { school climate, permanent teacher training, stimulus } \\
\text { system, complementary academic organization, } \\
\text { family-school relations, etc.) with greater impact on } \\
\text { the results. Develop actions aimed at improving the } \\
\text { non-cognitive abilities of students. }\end{array}$ \\
\hline
\end{tabular}

\begin{tabular}{ll}
\hline & $\begin{array}{l}\text { Undertake coordinated policies by the State and } \\
\text { the Autonomous Community, of a general nature } \\
\text { and specifically focused on disadvantaged sectors. } \\
\text { Murcia }\end{array} \quad \begin{array}{l}\text { Mobilizing, with criteria of efficiency, the material, } \\
\text { human and knowledge resources necessary to save } \\
\text { these situations of frank regional disadvantage. } \\
\text { Promote actions aimed at improving the non-cognitive } \\
\text { abilities of students. }\end{array}$ \\
\hline
\end{tabular}

Note: The + or - signs of the table indicate values of each of the three variables considered higher or lower respectively to the corresponding national averages.

Source: Authors' own work. 


\section{References}

Ashby, W. R. (1956). An introduction to cybernetics. London: Chapman \& Hall.

BIAC (2016). Business Priorities for Education. A BIAC Discussion Paper. Retrieved from http: / / biac.org/wp-content/uploads/2016/06/16-06-BIAC-Business-Priorities-for-Education1.pdf

Coll Serrano, V., \& Blasco Blasco, O. M. (2006). Evaluación de la eficiencia mediante el análisis envolvente de datos. Introducción a los modelos básicos. Valencia: B-EUMED 2000. Retrieved from www.eumed.net/libros/2006c/197/

Consejo Escolar del Estado (2015). Informe 2015 sobre el estado del sistema educativo. Curso 2012-2013. Madrid: Ministerio de Educación, Cultura y Deporte.

Cordero Ferrera, J. M., Crespo Cebada, E., Pedraja Chaparro, F., \& Santín González, D. (2011). Exploring educational efficiency divergences across spanish regions in PISA 2006. Revista de Economía Aplicada, 57(XIX), 117-145.

Cordero Ferrera, J. M., Pedraja Chaparro, F., \& Salinas Jiménez, J. (2005). Eficiencia en educación secundaria e inputs no controlables: sensibilidad de los resultados ante modelos alternativos. Hacienda Pública Española/ Revista de Economía Pública, 173(2/2005), 61-83.

Fadel, C., Bialik, M., \& Triling, B. (2015). Four-dimensional education. The competence learners need succeed. Center for Curriculum Redesign. Retrieved from http://curriculumre design.org/our-work/four-dimensional-21st-century-education-learning-competencies -future-2030/

Flamant, M. (1988). L'Histoire du liberalism. Paris: P.U.F.

Hattie, J. (2003). Teachers make a difference: What is the research evidence? Australian Council for Educational Research Annual Conference on Building Teacher Quality. October, $1-17$.

Kaufmann, D., Kraay, A., \&Zoido-Lobatón, P. (1999a). Aggregating governance indicators. World Bank Policy Research, Working Paper no. 2195. Retrieved from www.worldbank .org/wbi/governance.

Kaufmann, D., Kraay, A., \& Zoido-Lobatón, P. (1999b). Governance matters. World Bank Policy Research, Working Paper no. 2196. Retrieved from www.worldbank.org/wbi/governance.

López Rupérez, F. (2001). Preparar el futuro. La educación ante los desafíos de la globalización. Madrid: La Muralla.

López Rupérez, F., García García, I., \& Expósito Casas, E. (2017). La calidad de la gobernanza del sistema educativo español. Un estudio empírico. Madrid: Universidad Camilo José Cela.

López Rupérez, F., \& García García, I. (2017). Valores y éxito escolar. ¿Qué nos dice PISA 2015? Universidad Camilo José Cela. Retrieved from https: / / www.ucjc.edu/la-universidad /estructura-academica/catedras/catedra-politicas-educativas/\#pane-0-3.

Mandl, U., Dierx, A., \& Ilzkovitz, F. (2008). The effectiveness and efficiency of public spending. Economic Papers, 301. European Commission. Brussels: Directorate-General for Economic and Financial Affairs Publications. Retrieved from http://ec.europa.eu/economy_finance /publications.

Méndez, I., Zamarro, G., García Clavel, J., \& Hitt, C. (2015). Habilidades no cognitivas y diferencias de rendimiento en PISA 2009 entre las Comunidades Autónomas españolas. Participación Educativa, 2a época, 4, 51-61. Retrieved from http://ntic.educacion.es /cee/revista/n6.

Mingat, A., Tan, J. P., \& Sosale, S. (2003). Tools for education policy analysis. Washington, DC: World Bank.

Ministry of Education, Culture and Sports (2017). Las cifras de la educación en España. Curso 2014-2015. Retrieved from https://www.mecd.gob.es/servicios-al-ciudadano-mecd /estadisticas/educacion/indicadores-publicaciones-sintesis/cifras-educacion-espana .html.

OECD (2001). Measuring productivity. OECD Manual. Paris: OECD.

OECD (2010). PISA 2009 results: What students know and can do. Student performance in reading, mathematics and science (Volume I). Paris: OECD Publishing. Retrieved from http:// dx.doi.org/10.1787/9789264091450-en. 
36 OECD (2013). Résultats du PISA 2012: L'équité au service de l'excellence (Volume II): Offrir à chaque élève la possibilité de réussir. Paris: Éditions OCDE. Retrieved from http://dx.doi .org/10.1787/9789264205321fr.

OECD (2014). PISA 2012 results: What students know and can do. Student performance in mathematics, reading and science (Volume I, Revised edition, February 2014). Paris: OECD Publishing. Retrieved from http://dx.doi.org/10.1787/9789264201118-en.

OECD (2016). Résultats du PISA 2015 (Volume l): L'excellence et l'équité dans l'éducation. Paris: Éditions OCDE. Retrieved from http://dx.doi.org/10.1787/9789264267534-fr.

Stevenson, H. W., \& Stigler, J. W. (1992). The learning gap: Why our schools are failing and what we can learn from Japanese and Chinese education. New York: Touchstone.

UNESCO (2004). Education for all. The quality imperative. EFA global monitoring report 2005. Paris: UNESCO.

Villar, A. (coord.) (2012). Educación y desarrollo, PISA 2009 y el Sistema Educativo Español. Madrid: Fundación BBVA. Retrieved from https: //www. fbbva.es/wp-content/uploads /2017/05/dat/DE_2012_IVIE_educacion_desarrollo.pdf.

Willms, J. D. (2006). Learning divides: Ten policy questions about the performance and equity of schools and schooling systems (Working Paper no. 5). Instituto de Estadística de la UNESCO, Montréal, Canada.

World Bank (1992). World development report 1992. Development and the Environment. New York: Oxford University Press. Retrieved from https: //openknowledge.worldbank.org /handle/10986/5975.

Worthington, A. C. (2001). An empirical survey of frontier efficiency measurement techniques in education. Education Economics, 9(3).

Dr. Francisco López Rupérez Facultad de Educación. Cátedra de Políticas Educativas Universidad Camilo José Cela

Castillo de Alarcón, 49 28692 Madrid, Spain franciscolopezruperez@gmail.com

Prof. Isabel García García Facultad de Educación Universidad Camilo José Cela

Castillo de Alarcón, 49 28692 Madrid, Spain isabel.garciagarcia@gmail.com

Dr. Eva Expósito-Casas

Facultad de Educación Universidad Nacional de Educación a Distancia

Calle Juán del Rosal, №14 28040 Madrid, Spain evaexpositocasas@edu.uned.es 